\title{
Espaçamentos entre plantas e cobertura do solo com cama-de-frango na produção de ervilhas
}

\author{
Néstor Antonio Heredia Zárate; Rosimeire Pereira Gassi ("); Maria do Carmo Vieira; \\ Luciane Almeri Tabaldi; Elissandra Pacito Torales; Fabiane Cargnin Faccin \\ Universidade Federal da Grande Dourados (UFGD), Faculdade de Ciências Agrárias, Caixa Postal 322, 79825-480 Dourados (MS), Brasil. \\ (*) Autora correspondente: rpgassi@yahoo.com.br
}

Recebido: 12/jul./2011; Aceito: 9/dez./2011

\begin{abstract}
Resumo
O presente trabalho teve por objetivo avaliar a produção agroeconômica da ervilha Luciana n. ${ }^{\circ}$ 50, cultivada sob três espaçamentos entre plantas (5,0; 7,5 e 10,0 cm), com e sem cobertura do solo com cama-de-frango. Os tratamentos foram arranjados como fatorial 3×2, no delineamento experimental de blocos casualizados, com cinco repetições. As maiores massas frescas $\left(8,33 \mathrm{t} \mathrm{ha}^{-1}\right)$ e secas $\left(2,02 \mathrm{t} \mathrm{ha}^{-1}\right)$ da parte aérea foram das plantas cultivadas sob espaçamento de 7,5 cm e as menores (7,87 t ha-1 e 1,82 $\left.\mathrm{t} \mathrm{ha}^{-1}\right)$ foram daquelas sob 10,0 cm. A maior massa fresca de vagem comercial $(3,08 \mathrm{t} \mathrm{ha-1})$ foi das plantas cultivadas sob espaçamento de $5,0 \mathrm{~cm}$, superando em $0,33 \mathrm{t} \mathrm{ha}^{-1}$ àquelas sob $7,5 \mathrm{~cm}$, que foi a menor. A produção de massa fresca de vagens comerciais das plantas cultivadas sem cama-de-frango superou em 0,46 t ha-1 àquelas cultivadas no solo coberto com a cama-de-frango. A maior produção de grãos comerciais (2,24 t ha-1) foi das plantas cultivadas no solo sem cobertura com cama-de-frango. Considerando a produtividade de grãos comercializáveis e a estimativa da renda líquida $\left(\mathrm{R} \$ 5145,60 \mathrm{ha}^{-1}\right)$, conclui-se que a cultivar Luciana n. ${ }^{\circ} 50$ deve ser cultivada com espaçamento de $5,0 \mathrm{~cm}$ entre plantas no canteiro e sem o uso de cama-de-frango.
\end{abstract}

Palavras-chave: Pisum sativum, população de plantas, resíduo orgânico, renda bruta e líquida.

\section{Spacing between plants and soil covering with poultry litter on pea yield}

\begin{abstract}
The aim of this study was to evaluate the agroeconomic yield of 'Luciana n.o 50' pea grown within three spacings between plants (5.0; 7.5 and $10.0 \mathrm{~cm}$ ), with and without soil covering with poultry litter. Treatments were arranged in a $3 \times 2$ factorial in randomized complete block design with five replications. The highest fresh $\left(8.33 \mathrm{t} \mathrm{ha}^{-1}\right)$ and dry $\left(2.02 \mathrm{t} \mathrm{ha}^{-1}\right)$ shoot weights were of plants grown with spacing of $7.5 \mathrm{~cm}$ between plants, and the lowest fresh $\left(7.87 \mathrm{t} \mathrm{ha}^{-1}\right)$ and dry $(1.82 \mathrm{t} \mathrm{ha-1})$ weights were of those with $10.0 \mathrm{~cm}$. The highest fresh weight of commercial pods (3.08 $\mathrm{t} \mathrm{ha}^{-1}$ ) was found in plants grown with spacing of $5.0 \mathrm{~cm}$, exceeding by $0.33 \mathrm{t} \mathrm{ha}^{-1}$ those with $7.5 \mathrm{~cm}$. Fresh weight yield of commercial pods of plants grown without the use of poultry litter exceeded by $0.46 \mathrm{t} \mathrm{ha}^{-1}$ those grown with covering. The highest yield of commercial grains $\left(2.24 \mathrm{t} \mathrm{ha}{ }^{-1}\right)$ was obtained with plants grown in soil without covering. Considering the yield of commercial grains and the estimative of net income $\left(R \$ 5145.60 \mathrm{ha}^{-1}\right)$, it is concluded that the Luciana n. ${ }^{\circ} 50$ cultivar should be grown with spacing of $5.0 \mathrm{~cm}$ between plants per plot and without the use of poultry litter.
\end{abstract}

Key words: Pisum sativum, population of plants, organic waste, gross and net income.

A ervilha (Pisum sativum L., Fabaceae) é um dos vegetais cultivados mais antigos no planeta e está entre os dez mais consumidos. É originária do Oriente Médio e muito apreciada como legume ou consumida como gráos verdes ou secos e reidratados. No Brasil, o consumo restringia-se ao produto importado, devido às características climáticas necessárias à produção. Com a introdução, adaptação e desenvolvimento de tecnologia de produçáo de ervilha no Planalto Central, o Brasil reduziu sua importação em $70 \%$ nos últimos 20 anos (IAC, 2010).
Nas últimas décadas, diversas técnicas foram incorporadas ao cultivo de hortaliças, dentre elas, destaca-se a cobertura morta ou "mulching", prática pela qual se aplica ao solo material orgânico ou inorgânico como cobertura da superfície, induzindo menor perda de água por evaporação e diminuição das oscilaçôes da temperatura do solo. Além disso, o emprego da cobertura morta reduz a perda de nutrientes por lixiviaçáo e melhora os atributos físicos e químicos do solo (CARvalHo et al., 2005). No estádio vegetativo, nas plantas de ervilha submetidas ao excesso de água ocorrem murchamento, 
amarelecimento e senescência prematura das folhas mais velhas, principalmente na ramificaçáo principal. A redução da área fotossintética pode comprometer a produtividade no estádio reprodutivo (SÁ et al., 2004).

Para se obter melhores produtividades, especialmente de hortaliças pouco cultivadas como a ervilha, torna-se necessário estudar também outros tipos de tratos culturais como o arranjo de plantas, o qual pode ser manipulado por meio de alteraçóes na densidade de plantas, induzido pela distribuição de plantas na linha. De acordo com Heredia ZÁrATE et al. (2009), a população de plantas tem efeito marcante sobre a produção, já que a intercompetição por água, luz e nutrientes, em plantios densos, pode contribuir para a redução da capacidade produtiva das plantas, incidindo em maior ou menor grau na produtividade das diferentes espécies. Gassi et al. (2009), avaliando a capacidade produtiva da ervilha 'Luciana n. ${ }^{\circ} 50$ ' sob quatro e cinco fileiras no canteiro e três espaçamento entre plantas $(5,0$; 7,5 e $10,0 \mathrm{~cm}$ ), observaram que a maior produção de grãos tenros foram das plantas cultivadas sob quatro fileiras no canteiro e com espaçamento de $10 \mathrm{~cm}$ entre plantas.

Dessa forma, o presente trabalho teve por objetivo avaliar agroeconomicamente a ervilha Luciana n. ${ }^{\circ}$ 50, cultivada sob três espaçamentos entre plantas, com e sem cobertura do solo com cama-de-frango.

O experimento foi desenvolvido em Dourados (MS) entre junho e outubro de 2009, em latitude de $22^{\circ} 11^{\prime} 43^{\prime \prime}$ S, longitude de $54^{\circ} 56^{\prime} 08^{\prime \prime} \mathrm{W}$ e altitude de $458 \mathrm{~m}$. O clima, segundo a classificação de Köppen, é Mesotérmico úmido, do tipo Cwa, com temperaturas e precipitaçôes anuais variando, respectivamente de 20 a $24^{\circ} \mathrm{C}$ e de 1250 a 1500 $\mathrm{mm}$. O solo é do tipo Latossolo Vermelho distroférrico de textura muito argilosa (EMBRAPA, 1999).

Por meio da análise do solo, foram observados os seguintes resultados: 5,8 de $\mathrm{pH}$ em $\mathrm{H}_{2} \mathrm{O} ; 28,5 \mathrm{~g} \mathrm{dm}^{-3}$ de M.O; $8,7 \mathrm{mmol} \mathrm{dm}^{-3}$ de K; $65 \mathrm{mg} \mathrm{dm}^{-3}$ de P; $24,4 \mathrm{mmol} \mathrm{dm}^{-3}$ de Mg; 38,3 mmol $\mathrm{dm}^{-3} \mathrm{de}$ Ca; $124,3 \mathrm{mmol} \mathrm{dm}^{-3} \mathrm{de}$ CTC; $70 \mathrm{mmol} \mathrm{dm}^{-3} \mathrm{de}$ SB e $56 \%$ de V. A cama-de-frango foi analisada no Laboratório de Matéria Orgânica e Resíduos, em Viçosa (MG) e possuía $18,20 \%$ de $\mathrm{C}_{\text {orgânico; }} ; 0,89 \%$ de $\mathrm{P}_{\text {total }}$; $0,58 \%$ de $\mathrm{K}_{\text {total }} ; 2,01 \%$ de $\mathrm{N}_{\text {total }} ; 6,56 \%$ de $\mathrm{Ca}_{\text {total }} ; 0,57 \%$ de $\mathrm{Mg}_{\text {total }}$ e 9,05 de relaçáo C/N.

Foi estudada a ervilha Luciana n. ${ }^{\circ} 50$, cultivada sob três espaçamentos entre plantas $(5,0 ; 7,5$ e $10,0 \mathrm{~cm})$ correspondendo às populaçôes de 264.000; $351.912 \mathrm{e}$ 528.000 plantas ha ${ }^{-1}$, com e sem cobertura do solo com cama-de-frango e quatro fileiras no canteiro, com espaçamento de $25 \mathrm{~cm}$. Os tratamentos foram arranjados em esquema fatorial $3 \times 2$, no delineamento experimental de blocos casualizados, com cinco repetiçóes. As parcelas tinham área total de $3,00 \mathrm{~m}^{2}(1,50 \mathrm{~m}$ de largura por 2,00 $\mathrm{m}$ de comprimento) e área útil de 2,00 $\mathrm{m}^{2}$ (1,0 m de largura e 2,00 m de comprimento).

Para a instalaçáo do experimento, o terreno foi preparado com araçáo, gradagem e levantamento dos canteiros com rotoencanteirador. Para a semeadura, foram abertos sulcos de aproximadamente $0,05 \mathrm{~m}$ de largura $\mathrm{x} 0,05 \mathrm{~m}$ de profundidade, onde foram colocadas as sementes. Após a semeadura foi distribuída, manualmente e a lanço $10 \mathrm{t} \mathrm{ha}^{-1}$ de cama-de-frango semidecomposta na cobertura do solo.

Os tratos culturais consistiram em irrigaçóes, utilizando o sistema de aspersão, com turnos de rega a cada dois dias e capinas, com enxada entre os canteiros e manualmente dentro dos canteiros, sempre que necessário. Não houve infestaçôes de pragas ou infecçôes por fitopatógenos.

A colheita foi realizada aos 105 dias após a semeadura, quando nas plantas havia mais de $50 \%$ de senescência das folhas, época em que foram avaliadas as produçóes de massas fresca e seca da parte aérea, de vagens comerciais e não comerciais, de grãos comerciais e número de vagens comerciais. Além disso, foram medidos comprimento, largura e espessura das vagens comerciais e não comerciais.

Os dados obtidos foram submetidos à análise de variância e quando se verificou significância pelo teste $\mathrm{F}$, para a comparação das médias referentes a espaçamentos entre plantas, aplicou-se o teste de Tukey, a 5\% de probabilidade.

Os custos de produçáo foram calculados utilizando tabelas adaptadas de Terra et al. (2006), para milho-doce (Zea mays L.). Para o cálculo da renda bruta, foram utilizados os preços pagos aos agricultores de Dourados (MS), em dezembro de 2010, por cada quilograma de grão verde de ervilha $\left(\mathrm{R} \$ 5,00 \mathrm{~kg}^{-1}\right)$. A renda líquida foi determinada pela renda bruta menos os custos de produção por hectare cultivado.

As massas frescas e secas da parte aérea, de vagens comerciais e não comerciais e de grãos comerciais, não foram influenciadas significativamente pela interação espaçamento entre plantas e pelo uso ou não da cobertura do solo com cama-de-frango.

As massas frescas e secas da parte aérea, de vagens não comerciais e de grãos comerciais, não foram influenciadas significativamente pelo espaçamento entre plantas. As maiores massas frescas (Tabela 1) e secas (Tabela 2) da parte aérea $\left(8,33 \mathrm{t} \mathrm{ha}^{-1}\right.$ e $2,02 \mathrm{t} \mathrm{ha}^{-1}$ respectivamente) foram das plantas cultivadas sob espaçamento de $7,5 \mathrm{~cm}$ e as menores $\left(7,87 \mathrm{t} \mathrm{ha}^{-1} \mathrm{e} 1,82 \mathrm{t} \mathrm{ha}^{-1}\right.$ respectivamente) foram daquelas sob espaçamento de $10,0 \mathrm{~cm}$. A massa fresca de vagem comercial foi influenciada significativamente pelos espaçamentos entre as plantas, cujo maior valor $(3,08 \mathrm{t}$ $\mathrm{ha}^{-1}$ ) foi aquele das plantas cultivadas sob espaçamento de $5,0 \mathrm{~cm}$ superando em $0,33 \mathrm{t} \mathrm{ha}^{-1}$ às cultivadas sob 7,5 $\mathrm{cm}$, com menor valor. Por outro lado, Gassi et al. (2009) observaram elevação na massa fresca de vagens comerciais com o aumento do espaçamento entre plantas, e atribuíram esse incremento à menor competição das plantas por fatores essenciais de crescimento como luz, água e nutrientes. 
Tabela 1. Massa fresca da parte aérea, de vagem comercial e não comercial, de grão comercial e número de vagens comerciais da ervilha Luciana n. ${ }^{\circ}$ 50, cultivada sob três espaçamentos entre plantas, em solo com e sem cobertura com cama-de-frango. Dourados (MS), 2009

\begin{tabular}{|c|c|c|c|c|c|}
\hline \multirow{3}{*}{ Fatores em estudo } & \multicolumn{4}{|c|}{ Massa fresca (t ha-1) } & \multirow{3}{*}{$\begin{array}{l}\text { Número } \\
\text { vagem } \\
\text { comercial } \\
\left(\text { mil ha-1) }^{-1}\right.\end{array}$} \\
\hline & \multirow[b]{2}{*}{ Parte aérea } & \multicolumn{2}{|c|}{ Vagem } & \multirow[b]{2}{*}{$\begin{array}{c}\text { Grão } \\
\text { comercial }\end{array}$} & \\
\hline & & Comercial & $\begin{array}{c}\text { Não } \\
\text { comercial }\end{array}$ & & \\
\hline \multicolumn{6}{|l|}{ Espaçamento (cm) } \\
\hline 5,0 & $8,30 \mathrm{a}$ & $3,08 \mathrm{a}$ & $1,04 \mathrm{a}$ & $2,23 \mathrm{a}$ & $852 \mathrm{a}$ \\
\hline 7,5 & $8,33 \mathrm{a}$ & $2,75 b$ & $1,00 \mathrm{a}$ & $1,96 \mathrm{a}$ & $814 \mathrm{a}$ \\
\hline 10,0 & $7,87 \mathrm{a}$ & $2,87 \mathrm{ab}$ & $0,98 \mathrm{a}$ & $1,87 \mathrm{a}$ & $811 \mathrm{a}$ \\
\hline \multicolumn{6}{|l|}{ Cobertura do solo } \\
\hline Com & $8,18 \mathrm{a}$ & $2,67 \mathrm{~b}$ & $0,88 b$ & $1,81 \mathrm{~b}$ & 796,87 a \\
\hline Sem & $8,05 \mathrm{a}$ & $3,13 \mathrm{a}$ & $1,14 \mathrm{a}$ & $2,24 \mathrm{a}$ & $855,69 \mathrm{a}$ \\
\hline CV(\%) & 15,26 & 8,48 & 17,15 & 14,01 & 19,83 \\
\hline
\end{tabular}

Médias seguidas da mesma letra, nas colunas, năo diferem entre si, pelo teste F para cobertura do solo e pelo teste de Tukey para espaçamento, p>0,05.

Tabela 2. Massa seca da parte aérea, de vagem comercial e não comercial e de grão comercial da ervilha Luciana n. ${ }^{\circ} 50$, cultivada sob três espaçamentos entre plantas em solo com e sem cobertura com cama-de-frango. Dourados (MS), 2009

\begin{tabular}{|c|c|c|c|c|}
\hline \multirow{3}{*}{ Fatores em estudo } & \multicolumn{4}{|c|}{ Massa seca (t ha-1) } \\
\hline & \multirow{2}{*}{ Parte aérea } & \multicolumn{2}{|c|}{ Vagem } & \multirow{2}{*}{$\begin{array}{c}\text { Grão } \\
\text { comercial }\end{array}$} \\
\hline & & Comercial & Não comercial & \\
\hline \multicolumn{5}{|l|}{ Espaçamentos $(\mathrm{cm})$} \\
\hline 5,0 & $1,95 \mathrm{a}$ & $1,01 \mathrm{a}$ & $0,17 \mathrm{a}$ & $0,56 \mathrm{a}$ \\
\hline 7,5 & $2,02 \mathrm{a}$ & $0,82 \mathrm{~b}$ & $0,14 \mathrm{a}$ & $0,49 \mathrm{a}$ \\
\hline 10,0 & $1,82 \mathrm{a}$ & $0,85 a b$ & $0,16 \mathrm{a}$ & $0,47 a$ \\
\hline \multicolumn{5}{|l|}{ Cobertura do solo } \\
\hline Com & $1,94 \mathrm{a}$ & $0,78 \mathrm{~b}$ & $0,15 b$ & $0,43 b$ \\
\hline Sem & $1,92 \mathrm{a}$ & $0,99 \mathrm{a}$ & $0,18 \mathrm{a}$ & $0,56 \mathrm{a}$ \\
\hline CV(\%) & 14,66 & 9,75 & 27,95 & 15,23 \\
\hline
\end{tabular}

Médias seguidas da mesma letra, nas colunas, năo diferem entre si, pelo teste $\mathrm{F}$ para o uso ou não de cobertura do solo e pelo teste de Tukey para espaçamento, p>0,05.

A massas fresca de vagens e de grãos comerciais foram afetadas significativamente pelo uso ou não da cobertura do solo com cama-de-frango (Tabela 1). As plantas cultivadas sem o uso da cama-de-frango tiveram as maiores produçóes de vagem comercial e grãos comerciais, sendo, 3,13 e 2,24 t ha ${ }^{-1}$ respectivamente. Esse resultado deve estar relacionado com o fato da cama-de-frango ter sido usada em cobertura e tenha induzido menor perda de água do solo por evaporação e, com isso, provavelmente os nutrientes tenham estado mais diluídos na solução do solo não afetando o "stand" de plantas e a produçáo de folhas, com decréscimo na produtividade de vagens e de grãos comerciais.

$\mathrm{O}$ número de vagens comerciais não foi influenciado significativamente pela interação nem pelos fatores de forma isolada (Tabela 1), permitindo supor que são características intrínsecas da espécie.

A massa seca das vagens comerciais foi influenciada pelos fatores em estudo de forma isolada e as massas secas de vagens não comerciais e grãos comerciais foram influenciadas apenas pelo uso ou náo da cobertura do solo com cama-de-frango (Tabela 2). A maior massa seca de vagem comercial $\left(1,01 \mathrm{t} \mathrm{ha}^{-1}\right)$ foi das plantas cultivadas com espaçamento de $5,0 \mathrm{~cm}$. Esse resultado mostra que, para vagens comercializáveis, o menor espaçamento não induziu à pressão populacional que diminuísse a capacidade produtiva da planta, devido à competição por fatores de crescimento tais como luz, nutrientes e água, o que poderia resultar em decréscimo da produção (MARSCHNER, 2005).

O comprimento, a largura e a espessura das vagens comerciais não foram influenciados significativamente pela interação entre espaçamentos entre plantas e pelo uso ou não da cobertura do solo com cama-de-frango, nem pelos fatores de forma isolada permitindo supor que são características intrínsecas da espécie. $\mathrm{O}$ valor médio de comprimento para vagem comercial $(8,32 \mathrm{~cm})$ obtido neste experimento foi superior aos 6,0 a $7,5 \mathrm{~cm}$ citados pela EMBRAPA (2010) para as cultivares Forró, Frevo, Pagode e Samba.

O custo estimado para produzir 1,0 ha de ervilha foi a diferença de R \$ 3.286,62 quando se utilizou espaçamento de $10 \mathrm{~cm}$ entre plantas sem o uso da cama-de-frango na cobertura do solo e o tratamento $5,0 \mathrm{~cm}$ entre plantas e uso de cama-de-frango (Tabela 3).

A maior produção de grãos comerciais $(2,58 \mathrm{t}$ ha 1) foi obtida com espaçamento de $5,0 \mathrm{~cm}$ entre plantas e sem o uso da cama-de-frango na cobertura do solo que induziu ganho de $\mathrm{R} \$ 4.507,36$ em relação ao tratamento $5,0 \mathrm{~cm}$ entre plantas e uso de $10 \mathrm{t} \mathrm{ha}^{-1} \mathrm{de}$ 


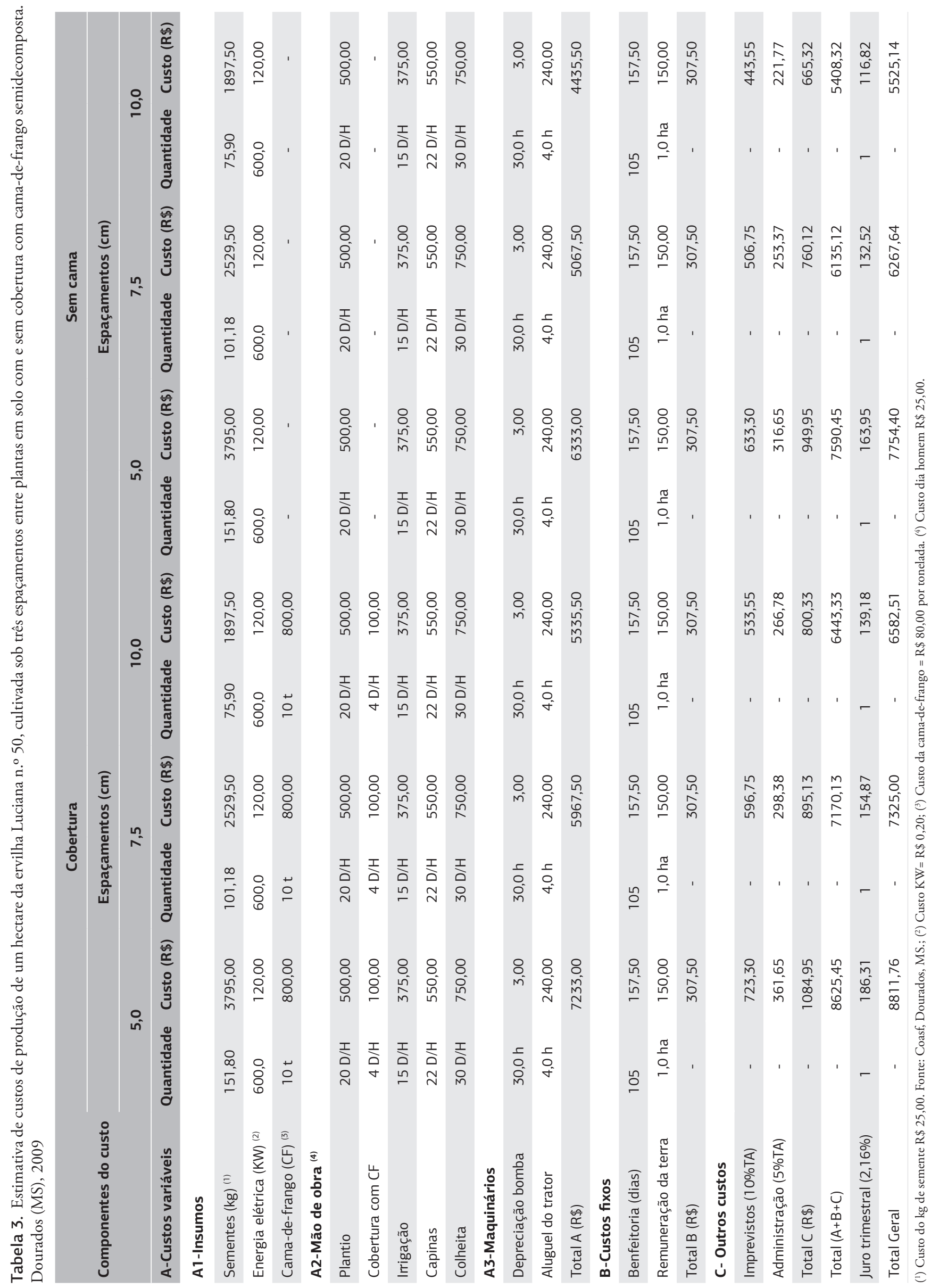


Tabela 4. Produção de grão comercial, renda bruta, custo de produção e renda líquida da ervilha Luciana n. ${ }^{\circ} 50$ cultivada sob três espaçamentos entre plantas, em solo sem e com cobertura cama-de-frango semidecomposta. Dourados (MS), 2009

\begin{tabular}{|c|c|c|c|c|c|}
\hline Cobertura do solo & $\begin{array}{l}\text { Espaçamento } \\
(\mathrm{cm})\end{array}$ & $\begin{array}{l}\text { Produção comercial } \\
\text { (t ha-1) }\end{array}$ & $\begin{array}{l}\text { Renda bruta }{ }^{(1)} \\
\left(\mathrm{R} \$ \mathrm{ha}^{-1}\right)\end{array}$ & $\begin{array}{l}\text { Custo de produção } \\
\left(\mathrm{R} \$ \mathrm{ha}^{-1}\right)\end{array}$ & $\begin{array}{l}\text { Renda líquida } \\
\left(\mathrm{R} \$ \mathrm{ha}^{-1}\right)\end{array}$ \\
\hline \multirow{3}{*}{ Com } & 5,0 & 1,89 & 9450,00 & 8811,76 & 638,24 \\
\hline & 7,5 & 1,88 & 9400,00 & 7325,00 & 2075,00 \\
\hline & 10,0 & 1,67 & 8350,00 & 6582,51 & 1767,49 \\
\hline \multirow{3}{*}{ Sem } & 5,0 & 2,58 & 12900,00 & 7754,40 & 5145,60 \\
\hline & 7,5 & 2,05 & 10250,00 & 6267,64 & 3982,36 \\
\hline & 10,0 & 2,08 & 10400,00 & 5525,14 & 4874,86 \\
\hline
\end{tabular}

(') $\mathrm{R} \$ 5,00 \mathrm{kgg}^{1}$ : preço pago ao produtor de ervilha de vagens na feira livre em Dourados (MS), em 2/10/2010.

( ${ }^{2}$ Renda bruta - custo de produção.

cama-de-frango, a menor renda líquida (Tabela 4). Esses resultados indicam que a análise econômica, isto é, a determinação de alguns índices de resultado econômico, deve ser feita para se conhecer com mais detalhes a estrutura produtiva da atividade e realizar as alteraçóes necessárias ao aumento de sua eficiência (Perez Júnior et al., 2006).

Para se obter maior produtividade de grãos comerciais e maiores rendas bruta e líquida, a ervilha Luciana n. ${ }^{\circ} 50$ deve ser cultivada com espaçamento de $5,0 \mathrm{~cm}$ entre plantas dentro das fileiras e sem o uso de cama-de-frango.

\section{AGRADECIMENTOS}

Ao CNPq, pelas bolsas concedidas e à FUNDECT-MS, pelo apoio financeiro.

\section{REFERÊNCIAS}

CARVALHO, J.E.; ZANELLA, F; MOTA, J.H.; LIMA, A.L.S. Cobertura morta do solo no cultivo de alface cv. Regina 2000, em Ji-Paraná/RO. Ciência e Agrotecnologia, v.29, p.935-939, 2005.

EMBRAPA. Centro Nacional de Pesquisa de Solos. Sistema brasileiro de classificaçáo de solos. Brasília: Embrapa Produção de Informação. Rio de Janeiro: Embrapa Solos, 1999. 412p.
EMBRAPA. Centro Nacional de Pesquisa de Hortaliças. Ervilha para produção de grãos verdes. Disponível em www.cnph.embrapa. br/cultivares/ervilha. Acesso em 20/8/2010.

GASSI, R.P.; HEREDIA ZÁRATE, N.A.; VIEIRA, M.C.; GOMES, H.E.; MUNARIN, E.E.; RECH, J. Espaçamentos entre plantas e número de fileiras no canteiro na produção de ervilha. Horticultura Brasileira, v.27, p.549-552, 2009.

HEREDIA ZÁRATE, N.A; VIEIRA, M.C; GRACIANO, J.D; FIGUEIREDO, P.G.; BLANS, N.B.; CURIONI, B.M. Produtividade de mandioquinha-salsa sob diferentes densidades de plantio e tamanho de mudas. Ciência e Agrotecnologia, v.33, p.139-143, 2009.

INSTITUTO AGRONÔMICO DE CAMPINAS. Centro de Análise e Pesquisa Tecnológica do Agronegócio de Grãos e Fibras. Disponível em: http://www.iac.sp.gov.br/Tecnologias/ ErvilhaGraos/ErvilhaGraos.htm. Acesso em: 25/8/2010.

MARSCHNER, H. Mineral nutrition of higher plants. 2.ed. Orlando: Academic Press, 2005. 889p.

PEREZ JUNIOR, J.H.; OLIVEIRA, L.M.; COSTA, R.G. Gestão estratégica de custos. 5.ed. São Paulo: Atlas, 2006. 378p.

SÁ, J.S.; CRUCIANI, D.E.; MINAMI.K. Efeitos de inundaçôes temporárias do solo em plantas de ervilha. Horticultura Brasileira, v.22, p. 50-54, 2004

TERRA, E.R.; HEREDIA ZÁRATE, N.A.; VIEIRA, M.C.; MENDONÇA, P.S.M. Proposta de cálculo e forma de adubação, com e sem amontoa, para a produçáo e renda bruta do milho Superdoce 'Aruba'. Acta Scientiarum. Agronomy, v.28, p.75-82, 2006. 